\title{
(Micro)Blogging Science? Notes on Potentials and Constraints of New Forms of Scholarly Communication
}

\author{
Cornelius Puschmann
}

\begin{abstract}
Academic publishing, as a practice and as a business, is undergoing the most significant changes in its 350-year history. Electronic journals and books, both Open Access and behind digital pay walls, are increasingly replacing printed publications. In addition to formal channels of scholarly communication, a wide array of semi-formal and informal channels such as email, mailing lists, blogs, microblogs, and social networking sites (SNS) are widely used by scientists to discuss their research (Borgman 2007, p. 47; Nentwich and König 2012, p. 50). Scholarly blogs and services such as Twitter and Facebook are increasingly attracting attention as new channels of science communication (see Bonetta 2007; Kjellberg 2010; Herwig et al. 2009). Radically different conceptualizations of scholarly (micro)blogging exist, with some users regarding them as a forum to educate the public, while others see them as a possible replacement for traditional publishing. This chapter will provide examples of blogs and microblogs as tools for scientific communication for different stakeholders, as well as discuss their implications for digital scholarship.
\end{abstract}

\section{Framing the Issue: New Forms of Scholarly Communication and Science 2.0}

There is a broad consensus that modern science is undergoing profound structural changes afforded by the rise of digital technology, and that this change is occuring on multiple levels of the scientific work process at once (Nielsen 2012; Nentwich and König 2012). The abundance of massive storage capacities, high volumes of processing power, and ubiquitous network access enables new forms of research which are contingent on large quantities of digital data and its efficient

C. Puschmann $(\bowtie)$

Humboldt University, Berlin, Germany

e-mail: puschmann@ibi.hu-berlin.de 
computational analysis (Weinberger 2011). This development is underscored by the rise of data science, that is, science that is driven by the analysis of large quantities of data from a wide range of sources such as sensors, scanners, MRI, telescopes, but also human-generated data from social media and digital libraries, and interrogated through statistical procedures, machine learning algorithms, and other computational instruments, allowing researchers to discover previously unrecognized patterns. Such approaches are innovative in the sense that they surpass the capabilities of traditional research in making observations of changes in very complex systems as they unfold, and in that they potentially allow predictions regarding the future behavior of such systems (Golder and Macy 2012). Whereas research has in the past been based upon comparably scarce evidence, the promise of data science is that it will be both scalable and reproducible on a previously unimaginable level, providing novel insights into a wide array of areas, from climatology to social science (Lazer et al. 2009) (Fig. 1).

\section{my experiment myExperiment makes it easy to find, use and share scientific workflows and other Research Objects, and to build communities.}

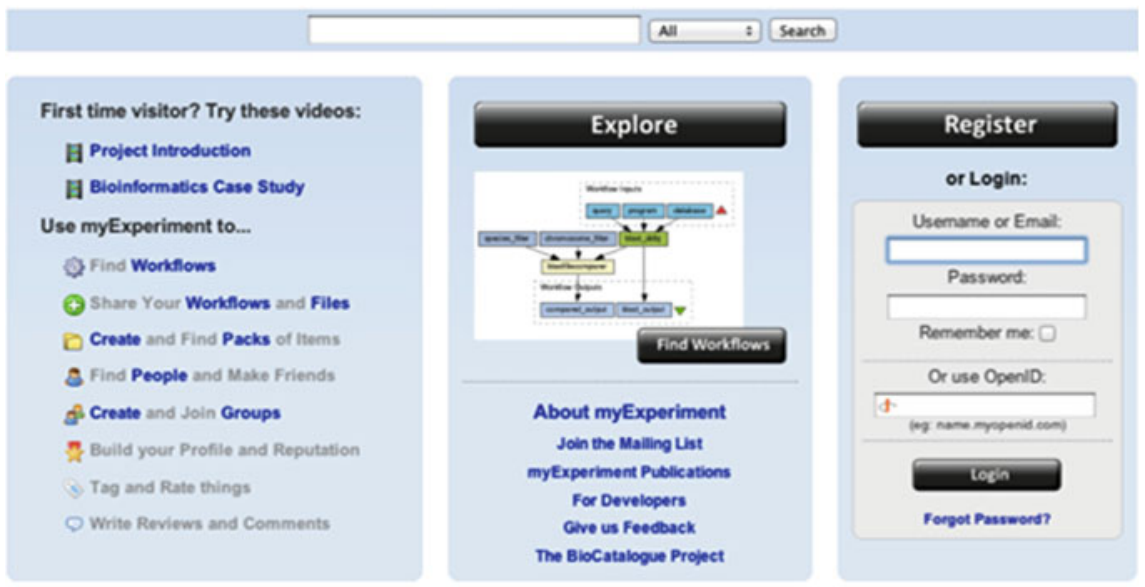

myExperiment has over 5000 members, 250 groups, 2000 workflows, 450 flies and 150 packs
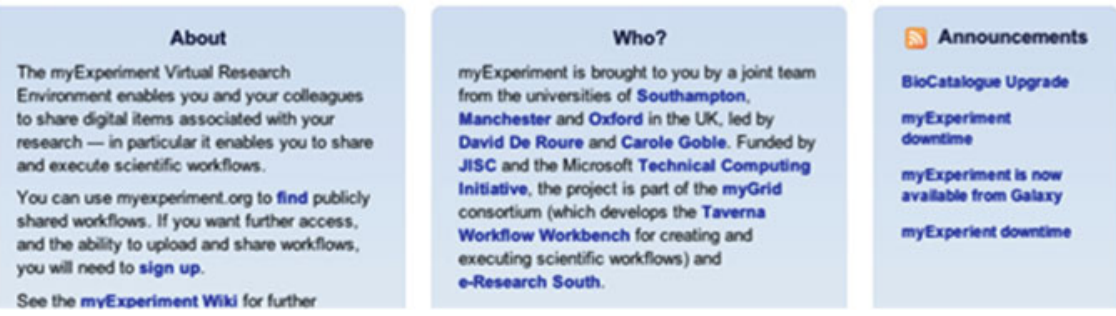

Fig. 1 myExperiment is one of a number of new virtual research environments (VREs) 
Beyond innovation of research methods, other aspects of how science is undertaken are also changing visibly, both as a result of technological shifts and because of economic and cultural changes in how research is financed and organized (cf. several contributions in this volume). From teaching and funding to publishing and peer review, it seems that a variety of aspects of how scientists work are changing, and that communication is at the forefront of this change, a change brought about primarily by the proliferation of technologies which are themselves the result of publicly funded scientific research. These technologies not only make it easier, cheaper, and quicker for scientists to exchange information with peers around the globe, they also have the potential to blur the line between internal communication among researchers and communication with the wider public. New formats must be adopted for scholarly use to fit the needs of academics while established genres evolve as a result of new technologies for the production and dissemination of scholarly publications (Cope and Kalantzis 2009).

Scientists have, of course, always been avid communicators. From Darwin's notebooks to the Large Hadron Collider, getting complex scientific issues across both to colleagues and laypersons has been at the top of the agenda for researchers for as long as modern science has existed. Successful communication is integral to scholarship because it allows scientific knowledge to proliferate, enable practical applications, and become entrenched societal knowledge, but also because frequently the outcomes of scientific research have far-reaching societal implications and are highly controversial (e.g., climate research, nuclear energy, genetics). Scientists must be able to explain what they do to a broader public to garner political support and funding for endeavors whose outcomes are unclear at best and dangerous at worst, a difficulty which is magnified by the complexity of scientific issues. They do so in an increasingly challenging environment, engaging with a public that has access to a wide range of sources of (by scientific standards) often dubious quality, many of them online (Puschmann and Mahrt 2012; König 2011). This public is increasingly critical and unimpressed by scientific authority and simple promises of scientific progress as an enabler of economic growth and societal welfare, and must be both won over and brought on board, rather than talked down to. Civil society expects to be engaged in a dialog with science, rather than being lectured. The affordances of social media (blogs, wikis, social networking sites) should accordingly be regarded as supporting a general long-term shift towards a more egalitarian relationship between experts and the lay public, rather than driving it (Fig. 2).

Intra-scientific discourse is changing as well, as a result of the move from paper to digital, which seems almost completed in much of the hard sciences. The majority of formal publishing in the STM disciplines takes place in academic journals and conference proceedings, with pre-prints, post-prints, reports, technical manuals, posters, and other formats also playing an important role (Borgman 2007). Increasingly, traditional academic genres (journal articles, conference papers, scholarly monographs) are published online, rather than in print, and disseminated through a variety of channels (email, blogs, online book reviews, 


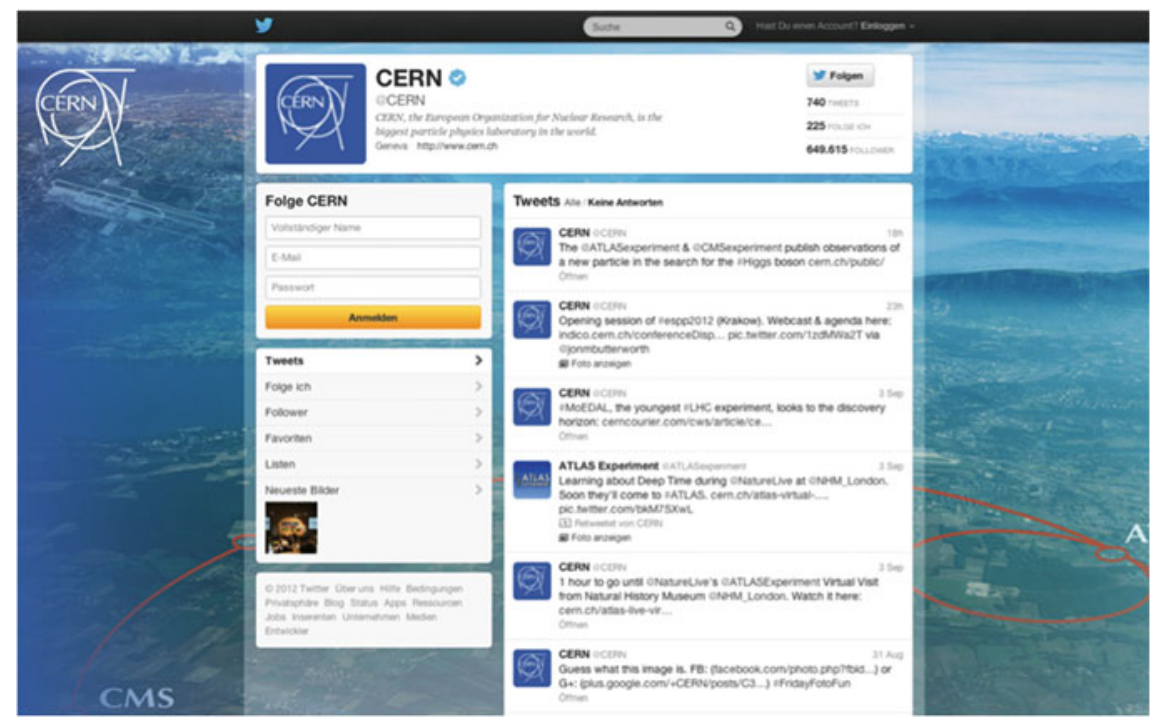

Fig. 2 CERN's Twitter page

social media). Preprint archives such as $\operatorname{arXiv}^{1}$ and Social Science Research Network (SSRN) ${ }^{2}$ have proliferated in a variety of disciplines and continue to grow in popularity. Beyond Open Access, there is an increased push for adding features that make use of the affordances of digital publishing, such as interactive charts and figures, and towards providing raw data along with papers to encourage follow-up research, for example on sites such as Figshare. ${ }^{3}$

\section{Science Blogging as a New Form of Engaging with Science}

While still an emergent phenomenon, new and genuinely digital forms of scholarly communication play an increasingly significant role in discussions about the future of academic discourse, especially as the existing system of knowledge dissemination is increasingly characterized as threatened or even dysfunctional (cf. Cope and Kalantzis 2009; Stein and Puschmann 2010). The phenomenon of science blogging has attracted significant attention and discussion in papers (e.g., Batts et al. 2008; Tola 2008; Shema et al. 2012) and at conferences (e.g., ScienceOnline '09, Science Blogging 2008: London). Sites such as Nature Network, ScienceBlogs.com, and

\footnotetext{
1 http://www.arXiv.org

2 http://www.ssrn.com/

3 http://www.figshare.com/
} 
Hypotheses.org act as hosting platforms of such specialized academic content, allowing researchers to present and discuss their work before a global audience, some with commercial publishers backing them, others funded publicly. Increasingly, universities and research institutes offer blog hubs which either aggregate externally-hosted content contributed by students and faculty members or allow direct publishing through the institutional website. Many academic researchers also rely on commercial hosting platforms such as Wordpress.com and Blogger.com to exchange information with peers and to document their projects.

A non-scholarly genre that has been adopted for scholarly communication, blogs are just one tool in a wider array of new formats. New platforms for publishing such as Open Journal Systems (OJS) and Annotum seek to make the processing and presentation of scholarly texts better adjusted to their digital environment. Monographs are also redefined in new approaches from initiatives such as PressForward or OpenEdition, which seek to modify both the dissemination of academic publications and the economics behind its distribution (costly production techniques, long delays between authoring and publication). Beyond making the results of scholarly research available online, efforts are being made to make scholarly formats themselves more innovative and better adjusted to the Internet (cf. Jankowski et al. 2012). The need to facilitate new means of knowledge production, presentation, and dissemination is widely felt, not only inside science itself, but also among policymakers. This need is fuelled both by the exponential growth of scholarly publishing (Jinha 2010) and the costs associated with the current model of subscription-based access. Different models have been proposed among the different varieties of Open Access (i.e. the 'gold road' model of immediate Open Access and the 'green road' model of delayed Open Access after an embargo period). Alternate funding schemes include author fees and institutional consortia, as well as direct public funding, for example via libraries (Houghton 2010).

Beyond the use outlined above-researchers using blogs to communicate their work, primarily to peers, a wide variety of other approaches to science (or, more broadly, scholarly) blogging exist, depending on communicators, target audience, and function. For example, it is widely assumed that because they are public, science blogs should be used to present the results of scientific research to a wider audience. Often blogging is seen as a new component of science journalism which is consequently something not just done by scientists, but also by journalists, or by enthusiasts with knowledge in a given area of science (Bonetta 2007). Frequently when the term science blogging (or scholarly blogging) is used, it is only implicitly clear which kind of blogging is meant, the variety that complements scholarly communication in journal articles and scholarly monographs, or the one that complements science journalism. It seems likely that different variants will continue to exist as a result of the freedom to innovate and create new genres online. In the following I will briefly discuss two different science blogs as examples of these different approaches in an attempt to underscore how blogging complements the needs of scientists and science communicators (journalists, activists, hobbyists) alike. While there is some overlap, it is important to be aware of the different needs of these actors. 
Table 1 Examples of actors, audiences, and functions of science blogs

\begin{tabular}{|c|c|c|c|}
\hline Actor & Target audience & Function & Analogy \\
\hline Lab leader in genetics & Funders, general public & $\begin{array}{l}\text { provide rationale } \mathrm{f} \text {. research } \\
\text { inform public \& funders }\end{array}$ & Report \\
\hline $\mathrm{PhD}$ student in physics & Peers, senior researchers & $\begin{array}{l}\text { promote self } \\
\text { practice writing }\end{array}$ & Lab notebook \\
\hline Science journalist & General public & $\begin{array}{l}\text { explain science broadly } \\
\text { educate readers }\end{array}$ & Magazine piece \\
\hline
\end{tabular}

Table 2 Example motives of science bloggers

\begin{tabular}{|c|c|c|}
\hline Motive A: Visibility & Motive B: Networking & Motive C: Information \\
\hline Increase own impact & Connect with peers & Be up to date \\
\hline $\begin{array}{l}\text { Be found by peers and } \\
\text { other stakeholders }\end{array}$ & Stay in touch with colleagues & Be part of a conversation \\
\hline Present self/own work & $\mathrm{Be}$ (come) part of a community & Anticipate trends \\
\hline
\end{tabular}

When approaching science blogs and an emergent communicative practice, it is helpful to first outline the roles they play for different stakeholders in the ecosystem of scholarly communication. Tables 1 and 2 give an overview of the various roles played by different actors, and of some of the motives of scientists who blog for different reasons, respectively.

\section{Case 1: Rosie Redfield (RRResearch)}

RRResearch is the blog of Rosemarie ('Rosie') Redfield, a microbiologist at the University of British Columbia, Vancouver, and head of the Redfield Lab at UBC's Department of Zoology. The blog was initially published on the commercial service Blogspot, but has since then moved to the independent blog network Field of Science ${ }^{4}$ which uses the Google Blogger platform ${ }^{5}$ as its technical backbone but is maintained so as to feature high quality scientific content contributed by experts from different fields.

Since August 2006, Redfield has posted over 900 entries on the blog, discussing various issues of her research. Her initial post gives a good idea about the direction of the blog:

\footnotetext{
4 http://www.fieldofscience.com/

5 http://www.blogger.com/
} 
This is my first post to this new blog.

The purpose of keeping the blog is to give me a semi-public place to describe the ongoing process of doing and thinking about my lab's research. I hope I'll use it to describe/explain (mainly to myself) the scientific issues I'm thinking about:

- what experiments we've done

- what the results were if they worked (or possible explanations for why they didn't work)

- what I think the results mean for the questions we're trying to answer

- what experiments I think we might do or should do when time and resources permit.

The purpose of this post, however, is mainly to see what happens when I click on 'Publish Post'

(from: http://rrresearch.fieldofscience.com/2006_08_01_archive.html)

While many posts are devoted to documenting and describing her researchoften, as emphasized in the post above, seemingly with herself in mind as reader, quite a few touch related issues relevant to a less specialized audience. For example, several early posts cover Bayesian statistics and discuss its use in genetics research. Many posts are related to meta-issues in scientific work, i.e. grant proposals, journal submissions, and other aspects that are part of work processes at a genetics laboratory.

While Redfield's blog was known to an expert audience before, she attained major success as a result the post "Arsenic-associated bacteria (NASA's claims)" (Redfield 2010) that strongly critiqued the paper "A Bacterium That Can Grow by Using Arsenic Instead of Phosphorus" (Wolfe-Simon et al. 2010) which had been previously published in the journal Science. In the blog post, Redfield initially reports the findings of the paper and then proceeds with a detailed criticism of the methodology used by the authors of the study. As in other entries, she mixes a somewhat informal style with the vocabulary of a scientific paper. She also includes numerous figures, illustrations, and references, making the post comparable to a review in a scientific journal (Fig. 3).

The post received over 250 comments and a polished version was later published by Science, though the original article was not retracted. Redfield's success in using her blog to voice her criticism, rather than using the traditional channels, was seen by many as a turning point in the dynamics of science communication-a journal widely recognized for its rigour saw itself forced to react to criticism posted in a blog.

RRResearch is the blog of a scientist, who accordingly uses it as part of a wider communicative agenda. While most writing done by academics is geared towards peers and written to withstand their scrutiny and criticism, writing a blog "for oneself" amounts to a space where freer, less regimented expression is possible. Redfield is, of course, aware that her blog is widely read, but its status as something 


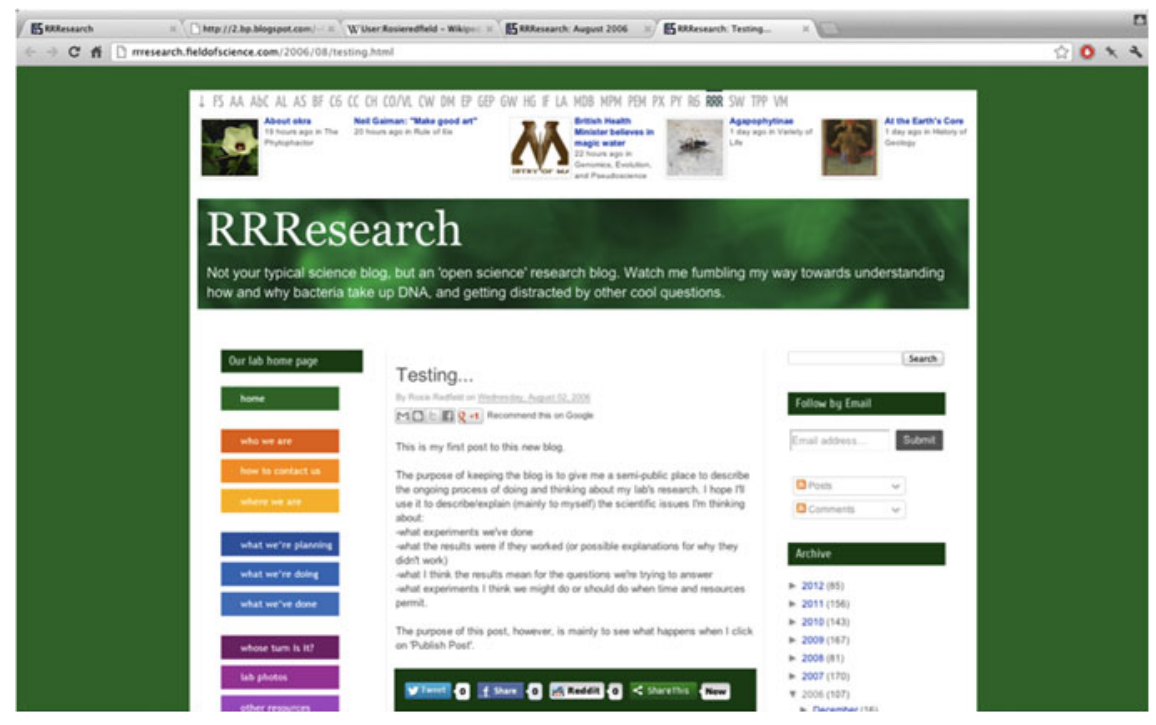

Fig. 3 The first post published on RRResearch in August 2006

other than a formally recognized publication is an asset, because it allows her to address issues that wouldn't generally fit into a formal publications. Yet $R R R e$ search is also not a typical science blog in the sense that most journalists or science educators would interpret the term-understanding much of what is published in it presupposes in-depth knowledge of biochemistry and Redfield makes no attempt to dumb down her writing to make it more palatable to a lay audience.

\section{Case 2: Bora Zivkovic (A Blog Around the Clock)}

Bora Zivkovic is a well-known blogger and science educator with a background in veterinary medicine and biology. He teaches introductory biology at North Caroline Wesleyan College, organizes ScienceOnline conference series, and has been a visiting scholar at New York University's Arthur L. Carter Journalism Institute.

Zivkovic started his site A Blog Around the Clock (ABATC) in 2006, after moving from Blogger.com to ScienceBlogs. In 2011, the blog was moved again, this time to Scientific American, where Zivkovic became the first Blog Editor. After he took up blogging in 2002, Zivkovic gradually gained wide recognition as a science blogger, not least because of the impressive volume of his activity. In the time before moving from Blogger to ScienceBlogs alone, he produced a total of 2420 posts about a variety of topics. While frequently these are short texts pointing to a news item, video, or other piece of information, many are detailed essays about (broadly) science and politics, science and the general public, etc. His style is not only less formal than that of Rosie Redfield, but he also uses considerably 
less scientific terminology. The considerable volume of content that flows through $A B A T C$ make it a virtual popular science magazine, covering a breadth of issues and formats (including blog carnivals and other outreach mechanisms that aim to strengthen connections with other blogs). Zivkovic both relays information from other sources, commenting on it and explaining it to readers, and provides longer commentaries, for example on issues of science policy. He assumes that his readers are interested in science, but does not generally presume in-depth knowledge of scientific topics. This approach is in line with Zivkovic's own background: while he is a trained scientist and writes from a first-hand perspective, his agenda is not that of someone paid for full-time research.

While RRResearch presents both the results of research (rarely) and frames scientific issues for a scientific audience, $A B A T C$ translates scientific topics for a more general, non-specialist audience. The issues are much broader there than they are in RRResearch, where they align much more strongly with the blogger's own research interests. The latter blog is a window into the mind and daily work of the researcher, not a friendly conversation with a lay audience. This is not to say that RRResearch doesn't engage — its success illustrates how well it achieves this goal-but whom it targets as its readership and what function it wants to realize remains at least partially unclear. Redfield uses her blog to frame issues for herself and her peers, while Zivkovic blogs for a readership with their needs squarely in mind. Much of the research that he relays is not his own, while much of what is discussed in RRResearch is Redfield's own work, or closely related to it. Whereas Redfield regards her blog as an instrument for communicating what she is currently working on or issues she is more generally interested in, Zivkovic provides a service and measures its success, at least in part, by its popularity and the amount of feedback he receives, a form of impact that may well be less relevant to a blogger like Redfield, who might be primarily concerned with her blog's reception among her students and peers (Fig. 4).

\section{The Uses of Microblogs for Science: Two Scenarios}

Compared to blogging, which has a history that reaches back to the beginning of the Web itself, microblogs are still a relatively new form of communication. Microblogs share with "normal" blogs the sequential organization of information in dated entries, but they are usually constrained in length to facilitate scanning a large number of posts rapidly. Another point of distinction is that microblogs are typically centralized services rather than decentralized software packages that can be run from one's own webserver. Twitter is by far the most popular service, though competitors exist, both related specifically to science and for general use. ${ }^{6}$

\footnotetext{
6 An example for a specialized microblogging for scientists is ScienceFeed, which is part of the social networking functionality offered by ResearchGate, while App.net is an advertising-free microblogging service that promises to put the interest's of its (paying) members first.
} 


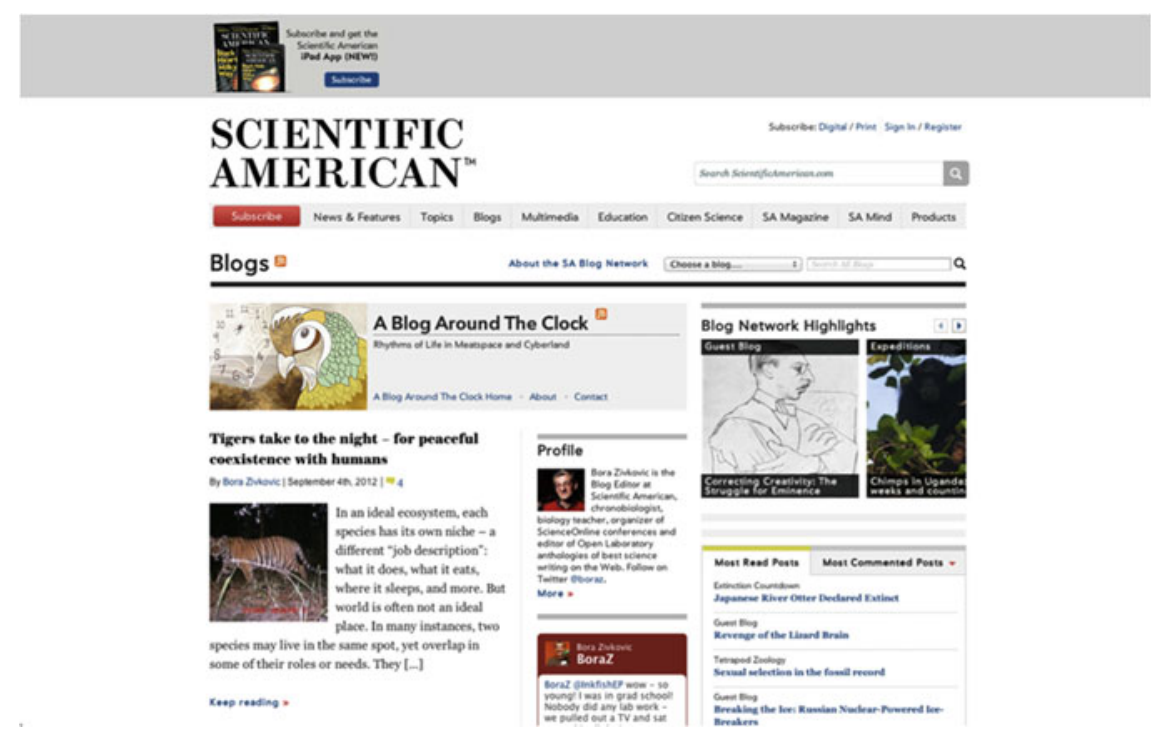

Fig. 4 A Blog Around the Clock, Bora Zivkovic's blog at the scientific American Blog network

As with blogs, the potential uses of microblogs for scholarly communication are highly varied, ranging from virtual journal clubs (Reich 2011) and debates about current, science-related events, to self-help for graduate students (for example, under the \#phdchat hashtag). Microblogs are also a way for scientists to stay up to date about what their colleagues are working on, while at the same time providing a window into current scientific research for science journalists and facilitating interaction between scientists and the general public (Puschmann and Mahrt 2012). The lack of a dividing line between scientists and non-scientists, as well as the great variety of topics that even scientists tweet about mean that Twitter is not comparable to the orderly world of science publishing, where every piece of information is assumed to be relevant. Instead, a typical user's timeline is likely to be populated both by scholarly content and personal remarks, more or less side by side. As the size of the network and the thematic broadness of Twitter is what makes it interesting to most users, it seems unlikely that this "problem" will ever be remedied at its core, but the ability to filter information from Twitter and similar services is likely to resolve the issue. ${ }^{7}$ Tweets and other social media information can congregate around a journal article or piece of data-an approach that may also be beneficial for the development of dedicated science services. Such services could eventually become a reality as the strengths of services like Twitter are at once also a weakness: while timely, tweets are not accessible in the long term, and increased brevity also means less nuanced information in each tweet.

\footnotetext{
7 As one example of a new approach to publishing powered by Twitter aggregation, see http:// digitalhumanitiesnow.org/
} 
Wide proliferation and ease of use may eventually be offset by problems regarding access to and long-term preservation of data. As with FriendFeed, ${ }^{8}$ which was enthusiastically embraced by a small community of scientists, it is completely unclear how Twitter will evolve and the concerns of academics are likely to matter very little in respect to this. It is conceivable that policymakers will eventually put into place an infrastructure that will support the kind of communication taking place on Twitter, at least between scientists, rather than leaving vital issues to private companies that do not have scientific issues at the center of their attention. While it is impossible to tell how many scientists are already using Twitter and similar services and in what ways, it is safe to say that the significance of microblogging is growing, while its role for science communication continues to evolve (cf. Puschmann and Mahrt 2012). In the following, two common scenarios for the use of microblogs will be described in more detail: tweeting at scientific conferences and using Twitter to cite papers in Open Access journals and repositories.

\section{Case 1: Twitter at Conferences}

Conferences are all about communication. When used in the context of scientific conferences, Twitter acts as a backchannel, in other words, it complements what happens at the conference itself, allowing attendees, and quite frequently also people who are unable to attend, to comment, ask questions, and participate in the discussion taking place. It is important to point out that this complements the face to face activity, rather than replacing it. It is a major advantage that a talk can take place uninterrupted while a lively discussion takes place about it on Twitter. A drawback of this approach is that the presenter cannot participate in the debate while it is underway and while being the the subject of discussion, sometimes also criticism. The use of a Twitter wall, i.e. a projection of hashtagged tweets usually shown next to or behind the presenter, can aggravate this problem. In November 2009, social media researcher Danah Boyd held a talk at the media industry event WebExpo New York that was accompanied by a Twitter wall showing tweets posted under the conference hashtag. As Boyd delivered her presentation, which was beset by technical difficulties, she was the subject of intense polemical remarks from spectators via Twitter; all the while, she herself could not see the projection of the offensive tweets as she spoke. Though this kind of incident is rare, it underlines the double-sidedness of a technology that is open and easy to use, but therefore also easy to abuse under certain circumstances. Twitter walls, apart from being a distraction, seem to add fairly little communicatively to the overall conference, although their precise placement (e.g. in the lobby, rather the main conference hall) seems a key issue to be aware of (Fig. 5).

${ }^{8}$ http://friendfeed.com/ 
Fig. 5 Network visualization of retweets among users at the World Wide Web 2010 Conference (\#www2010), held in April 2010 in Raleigh, North Carolina

Examining the usage of Twitter during conferences, it is notable how specific the usage of scientists is compared to users of different backgrounds, and that at the same time microblogging is always more informal communication than traditional publishing, not just because of its brevity. Rather than chatting idly, researchers share information via Twitter - they point to papers and posters, to datasets online, and to websites related to their research (Weller and Puschmann 2011). Passing on (retweeting) this information is extremely popular, more so than just exchanging pleasantries or gossip. At the same time, academics also link to the same resources that other users do, such as online picture services such as Instagram or Twitpic or video platforms like YouTube and Vimeo (Thelwall et al. 2012), and they link to a variety of popular science content, i.e. science articles from newspapers (Weller et al. 2011). The continuum between personal and professional is frequently blurred on microblogging platforms. Conferences act as a sort of content filter-because the event that a conference hashtag is associated with is all about a professional activity, what is tweeted under the hashtag is usually related fairly closely to the topic of the event, though meta-topics such as the conference program or pointers to the venue of conference venue are also popular. 


\section{Case 2: Twitter for Citations}

Beyond conferences, Twitter also plays an increasingly important role for day-today communication among scientists. Academics are often interested in a variety of topics outside of their specific field of research and accordingly tweet about many things which are the not subject of their work or comment in ways that differ from traditional scholarly communication. This highlights an issue of informal digital communication online: it is extremely hard to determine what constitutes a scientifically "valuable" contribution and what does not. While some tweets are related to scholarly issues and others are obviously personal in nature, many occupy a meso-level between what is traditionally considered scholarly content and what usually is not. Counting every tweet mentioning a scholarly source as scientifically valuable is obviously too simplistic, as is discarding every personal remark as irrelevant.

This is a particularly salient issue because an increasing number of studies examine the relevance of social media for scientometrics, in other words, the role that social media can play in measuring and predicting the impact of scientific research (e.g., Weller and Puschmann 2011; Eysenbach 2011). By conservative estimates, popular sites such as arXiv received around 5,000 links per month ${ }^{9}$ and this is bound to increase in the future. If the popular reception of scholarly literature among scientists and non-scientists alike via Twitter can be considered a form of impact (and many agree that it can), this means that citations on Twitter and via other channels may be introduced as a valid impact measure into the scientometric toolkit in the future [cf. the suggestions of Priem et al. (2011) in this direction].

\section{Who Uses Blogs and Microblogs for Scholarly Communication, and Why?}

In the environment of change outlined above, it is only logical to ask why new forms of communication online-blogs, Twitter, social networks-haven't proliferated to a greater extent. If the examples of innovative usage of blogs and Twitter to communicate among scientists and more broadly about science give a reason to be optimistic, actual usage of such tools among scientists-defined here as the broad base of academics employed for research and teaching at universities and research institutes-should caution enthusiasts. International studies on the acceptance rate of social media among scientists vary considerably in their results, but many suggest widespread skepticism (cf. Procter et al. 2010; Bader et al. 2012). ${ }^{10}$ While pointing to examples where new formats have succeeded is useful, it is also worth noting that

\footnotetext{
9 Author's own estimate based on ongoing tracking of all tweets linking to the arXiv website.

10 But see Priem et al. (2011), who suggests that usage of Twitter is steadily growing.
} 
scientists are conservative when it comes to embracing new technologies, both for internal communication and in relation to new means of engaging with the general public. This may be changing, but it seems important to consider both the muchcited potential of social media for science communication and the reality of its yet-nascent acceptance among faculty members-especially those in senior positions. For policymakers it is imperative to have an accurate picture of the situation and the immediate future, beyond lofty promises. It is exceedingly likely that in those areas where change is occurring because it is being driven, at least in part, by researchers themselves, the changes will be more lasting than where new technologies are not well-integrated into established practices. Further factors able to spur innovation are payback in the form of funding, increased reputation, and other critical competitive aspects of institutional science. Yet it remains unproven whether social media tools are essential to improving scholarly communication or whether their usefulness is restricted to the margin of science and scholarship, rather than extending to the center.

Two key components that could facilitate the success of social media tools (blogging, microblogging, but also wikis and social networking sites for scientists) are the spread of alternative means of measuring scientific impact beyond traditional bibliometric indicators (a) and the increasing adaptation of social media formats for science and integration into "proper" scientific discourse (b). The former is at the focus of innovations in scientometrics and initial suggestions are likely to be made in the coming years to funders and research organizations about how to measure impact more holistically, though it remains to be seen whether established (and widely criticized) measures such as Thompson Scientific's Impact Factor (IF) can be displaced. In order to achieve the latter, the institutional enablers of science communication-publishers, libraries, science organizations and scholarly societies-will have to invent not only new technologies, but also rebrand familiar labels that scientists rely on. The French site Hypotheses.org and the lab platform OpenWetWare.org are examples of this approach: while the former is a technically a blog platform based on the popular Wordpress software and the latter is a wiki based on Wikimedia's MediaWiki, both clearly present themselves as pieces of scientific infrastructure, built for an academic audience. Success in these approaches lies not in engaging with the "newness" of social media to win skeptics over, but in promising that social media tools can be adapted to achieve similar aims as were previously realized through other channels, only quicker, cheaper and with broader effect.

The current consensus among scientists appears to be that blogs and Twitter are somewhat interesting to promote one's own research (to journalists and perhaps a few colleagues), and more broadly, one's field (to potential students, the general public), but that the payoff is not always worth the time and effort (Bader et al. 2012). If science was solely concerned with getting scholarly content across to as many people as possible, blogs would have displaced the established system of academic publishing by now, but it is no coincidence that the journal article has not been abandoned in favor of the blog post. In addition to overall conservatism, the lack of peer review in social media channels also hampers its adoption as a 
Table 3 Advantages and disadvantages of blogging and microblogging

\begin{tabular}{|c|c|c|c|}
\hline Blogs & & Twitter & \\
\hline+ & - & + & - \\
\hline $\begin{array}{l}\text { Rapidly } \\
\text { disseminate } \\
\text { content }\end{array}$ & Lack of formal recognition & $\begin{array}{l}\text { Communicate with } \\
\text { colleagues }\end{array}$ & Time-consuming \\
\hline Cheap & $\begin{array}{l}\text { Lack of prestige in the } \\
\text { scientific community }\end{array}$ & $\begin{array}{l}\text { Promote your } \\
\text { research }\end{array}$ & Benefits unclear \\
\hline Easy to use & No clear topical focus & $\begin{array}{l}\text { Disseminate } \\
\text { information }\end{array}$ & $\begin{array}{l}\text { Increased self- } \\
\text { exposure }\end{array}$ \\
\hline $\begin{array}{l}\text { Open to } \\
\quad \text { individuals }\end{array}$ & Time-consuming & $\begin{array}{l}\text { Build personal } \\
\text { influence }\end{array}$ & $\begin{array}{l}\text { Not sufficiently } \\
\text { informative }\end{array}$ \\
\hline $\begin{array}{l}\text { Promotional } \\
\quad \text { tool }\end{array}$ & $\begin{array}{l}\text { Long-term availability } \\
\text { unclear }\end{array}$ & $\begin{array}{l}\text { Stay up to date about } \\
\text { your field }\end{array}$ & $\begin{array}{l}\text { Perceived as } \\
\text { trivial }\end{array}$ \\
\hline
\end{tabular}

replacement for traditional publications. Scholarly content, regardless of the discipline, must be valorized by the judgement of others, and frequently only after the criticism of peers has been taken into account and the original manuscript has been adjusted is a piece of writing deemed a genuine scholarly publication. Time is the scarcest resource in research and investing it in an activity of peripheral importance is widely regarded as wasteful. Taking the extreme goal-orientedness of scholarly communication into account is essential in understanding the perceived advantages and disadvantages of social media in the minds of many scientists (Table 3).

\section{Conclusion}

A comparably small number of people across the globe actively works on complex scientific issues, communicating through channels and genres established over the course of decades, or in some cases centuries, which have been carefully designed to suit the needs of the respective communities. How can those on the outside reasonably argue for the need to profoundly change such a system without professing their own status as outsiders? The underlying claim of those challenging science to be more open is that it is closed to begin with, a perception not universally shared by scientists. Those who espouse the view that social media should be used to discuss scientific research tend to fall into one of either two camps: adaptionists or revolutionaries. Adaptionists believe that social media tools need to suit researchers needs in doing what they are already doing. Hard adaptationists believe that new formats should replace established ones because they are more efficient, cheaper, faster, and better than the established formats of institutionalized academia (e.g. that blog posts should replace journal articles). Soft adaptionists believe that new forms should augment existing ones, often filling unaddressed needs. A soft adaptionist would use Twitter to promote his research, but not 
publish a paper in his blog rather than Nature. In practice, most adaptionists probably act as soft adaptionists, but some would prefer to follow the hard, uncompromising route if they could. Adaptionists have in common the basic belief in the legitimacy and relevance of the existing system of institutional science, but see it as being in need of reform. They believe that certain aspects of the system need change, but are convinced of its overall soundness. Revolutionaries, by contrast, call more than just specific aspects of the system (e.g. publishing) into question, being, in fact, opposed to the system as such, which they perceive as elitist and deeply flawed. While to the adaptationists science is fundamentally open, it is fundamentally closed to the revolutionaries, who are rarely themselves part of the entrenched academic system, but tend to be either junior faculty members or amateurs. Whereas the adaptationists have been co-opted to varying degrees to uphold the established order, the revolutionaries imagine a future in which the the entrenched system is overturned. Though the latter seems much less likely than the former, both groups actively advance the significance of social media for science, in spite of widespread inertia on the part of much of the academic establishment.

It has yet to be seen how exactly blogs and microblogs will fit into the existing ecosystem of scholarly publishing. Their role could be complementary, providing an outlet for purposes which traditional publishing does not address-from reflections about teaching to the promotion of a researcher's work. Miscellaneous writing that does not fit into recognized publications however is strongly contingent on the time that a researcher has at their disposal. Blogging on a regular basis is time-consuming, therefore it is likely that full-time academics will actively blog only if they find it benefits their career. In the end, blogs and microblogs supplement, rather than replace, traditional formats, and act as tools for the promotion of one's research, rather than tokens of prestige and academic excellence. Changing blogs in order to make them functionally equivalent to recognized formal publications would mean changing them to a degree that could nullify their benefits (for example, by introducing peer review). Instead, they have a place in the larger ecosystem of science communication 2.0 which includes protocols (OpenWetWare) and workflows (myExperiment) as examples of entirely new scientific genres which are functionally different from blog posts.

Open Access This chapter is distributed under the terms of the Creative Commons Attribution Noncommercial License, which permits any noncommercial use, distribution, and reproduction in any medium, provided the original author(s) and source are credited.

\section{References}

Bader, A., Fritz, G., \& Gloning, T. (2012). Digitale Wissenschaftskommunikation 2010-2011 Eine Online-Befragung, Giessen: Giessener Elektronische Bibliothek. Available at: http:// geb.uni-giessen.de/geb/volltexte/2012/8539/index.html [Accessed April 2, 2013]. 
Batts, S.A., Anthis, N.J., \& Smith, T.C. (2008). Advancing science through conversations: Bridging the gap between blogs and the academy. PLoS Biology, 6(9), p.e240.

Bonetta, L. (2007). Scientists enter the blogosphere. Cell, 129(3), 443-445.

Borgman, C. L. (2007). Scholarship in the digital age: information, infrastructure, and the Internet. Cambridge, Mass: MIT Press.

Cope, W.W., \& Kalantzis, M. (2009). Signs of epistemic disruption: Transformations in the knowledge system of the academic journal. First Monday, 14(46).

Eysenbach, G. (2011). Can tweets predict citations? metrics of social impact based on twitter and correlation with traditional metrics of scientific impact. Journal of Medical Internet Research, 13(4), e123.

Golder, S., \& Macy, M. (2012). Social Science with Social Media. ASA Footnotes, 40(1). Available at: http://www.asanet.org/footnotes/jan12/socialmedia_0112.html.

Herwig, J. et al., (2009). Microblogging und die Wissenschaft. Das Beispiel Twitter, Available at: http://epub.oeaw.ac.at/ita/ita-projektberichte/d2-2a52-4.pdf.

Houghton, J.W. (2010). Alternative publishing models: exploring costs and benefits. In C. Puschmann \& D. Stein, (Eds.), Towards Open Access Scholarship. Selected Papers from the Berlin 6 Open Access Conference (pp. 27-40). Düsseldorf: Düsseldorf University Press.

Jankowski, N.W. et al. (2012). Enhancing scholarly publications: developing hybrid monographs in the humanities and social sciences. SSRN Electronic Journal.

Jinha, A. E. (2010). Article 50 million: an estimate of the number of scholarly articles in existence. Learned Publishing, 23(3), 258-263.

Kjellberg, S. (2010). I am a blogging researcher: motivations for blogging in a scholarly context. First Monday, 15(8).

König, R. (2011). Wikipedia-participatory knowledge production or elite knowledge representation? Discussion pages as an arena for the social construction of reality. In Contribution to the workshop Participatory knowledge production 2.0: Critical views and experiences (pp.1-6). Virtual Knowledge Studio. Maastricht: Virtual Knowledge Studio.

Lazer, D., et al. (2009). Computational social science. Science, 323(5915), 721-723.

Nentwich, M., \& König, R. (2012). Cyberscience 2.0: research in the age of digital social networks, Frankfurt; New York: Campus Verlag.

Nielsen, M. A. (2012). Reinventing discovery: the new era of networked science. Princeton, N.J.: Princeton University Press.

Priem, J., Piwowar, H., \& Hemminger, B. (2011). Altmetrics in the wild: An exploratory study of impact metrics based on social media. Presented at Metrics 2011: Symposium on Informetric and Scientometric Research. New Orleans, USA, Oct 12, 2011.

Priem, J., Taraborelli, D., Groth, P., \& Neylon, C. (2011). Almetrics: a manifesto. Available at: http://altmetrics.org/manifesto/.

Procter, R., et al. (2010). Adoption and use of Web 2.0 in scholarly communications. Philosophical Transactions of the Royal Society A: Mathematical, Physical and Engineering Sciences, 368(1926), 4039-4056.

Puschmann, C., \& Mahrt, M. (2012). Scholarly blogging: A new form of publishing or science journalism 2.0? In A. Tokar et al. (Eds.), Science and the Internet (pp.171-181). Düsseldorf: University Press.

Redfield, R. (2010). Arsenic-associated bacteria (NASA's claims). RRResearch. Available at: http://rrresearch.fieldofscience.com/2010/12/arsenic-associated-bacteria-nasas.html.

Reich, E. S. (2011). Researchers tweet technical talk. Nature, 474(7352), 431-431.

Shema, H., Bar-Ilan, J., \& Thelwall, M. (2012) research blogs and the discussion of scholarly information C. A. Ouzounis, (Ed.), PLoS ONE, 7(5), e35869.

Stein, D., \& Puschmann, C. (2010). Timely or Timeless? The scholar's dilemma. thoughts on Open Access and the social contract of publishing. In D. Puschmann \& D. Stein (Eds.), Towards Open Access Scholarship. Selected Papers from the Berlin 6 Open Access Conference (pp.5-10). Düsseldorf: Düsseldorf University Press. 
Thelwall, M. et al. (2012) Chapter 9 Assessing the impact of online academic videos. In G. Widén \& K. Holmberg (Eds.), Social Information Research (pp.195-213). Library and Information Science. Bingley: Emerald Group Publishing.

Tola, E. (2008). To blog or not to blog, not a real choice there. JCOM Journal of Science Communication, 2(2).

Weinberger, D. (2011). Too big to know: rethinking knowledge now that the facts aren't the facts, experts are everywhere, and the smartest person in the room is the room. New York: Basic Books.

Weller, K., \& Puschmann, C. (2011). Twitter for scientific communication: How can citations/ references be identified and measured? In Proceedings of the ACM WebSci'11 (pp. 1-4). Koblenz: ACM Publishers.

Weller, K., Dröge, E., \& Puschmann, C. (2011). Citation analysis in Twitter. approaches for defining and measuring information flows within tweets during scientific conferences. In M. Rowe et al. (Eds.), Proceedings of Making Sense of Microposts (\#MSM2011). CEUR Workshop Proceedings. (pp.1-12), Heraklion, Greece.

Wolfe-Simon, F., et al. (2010). A bacterium that can grow by using arsenic instead of phosphorus. Science, 332(6034), 1163-1166. 